https://doi.org/10.46344/JBINO.2021.v10i04.15

\title{
MORPHOLOGICAL STUDIES ON THE AXIAL SKELETON OF THE WEST AFRICAN GIRAFFE (GIRAFFA CAMELOPARDALIS PERALTA).
}

\author{
Kenechukwu Tobechukwu ONWUAMA .,Alhaji Zubair JAJI.,Sulaiman Olawoye SALAMI \& Esther Solomon \\ KIGIR
}

Department of Veterinary Anatomy, Faculty of Veterinary Medicine, University of Ilorin, Ilorin, Nigeria

Email: kenexcares@yahoo.com

\begin{abstract}
The Skeletal system of any animal contributes largely to its morphology and conformation, at the same time, playing a major role in its physiology. To this end, this study was aimed at investigating the morphology and number of bones on the axial skeleton of the West African Giraffe (Giraffa Camelopardalis peralta). Two (2) adults obtained as carcass at different times after post-mortem examination were used. Bone preparation was achieved via cold water maceration after proper defleshing to reveal morphological features that showed differences and similarities to domesticated animal species. The skull presented unique and specific features peculiar to this mammal such as a highly convex dorsal surface of the frontal bone, spiral shaped superficial grooves radiating from the supraorbital foramen, short nasal bone with its valley shaped double pronged rostral projection and large irregular shaped frontal sinuses. The parietal bone was unpaired and caudally situated while the interparietal bone was absent. The Vertebral segments presented a formula C7 T14 L5 S4 C15-18. Evidence of neck lengthening was observed in the obvious elongated appearance of the cervical vertebra which resulted in the presence of peculiar features and absence of recognized features. The average total number of bones making up the axial skeleton was accounted to be 82 . In conclusion, this study has provided a baseline data for further biological and archeological studies.
\end{abstract}

Keywords: Gross anatomy; Skull; Vertebrae; West African Giraffe; Bone. 


\section{Introduction:}

The West African giraffe (Giraffa Camelopardalis), the tallest living terrestrial mammal and largest ruminant is a representative of the graffidae family of the order artiodactyla consisting of one species having multiple sub species (Fennessy et al., 2016; Bercovitch et al., 2017). It is a native of Africa, especially the sub-saharan regions with their distribution including several fragmented parts of the continent (Hassanin et al., 2007).

It has however been extirpated from much of their historical range due to different parts of their body being used for different purposes (Kingdon, 1997) therefore being listed as vulnerable (Muller et al., 2016. Fennesey et al., 2018) with some subspecies even endangered (Bolger et al., 2019). Though still found in numerous national parks and game reserves with a few in the wild (Pellow, 2001), its dwindling population has raised concerns for its protection and further domestication in private game reserves and zoos (Foley et al., 2014). Although studies on the various physiological, behavioural and biological aspects of this mammal has been conducted, none has been documented on the detailed description of the bones that make up its skeleton. To this end, this study on the axial skeleton has been conducted to investigate other specific gross features and number of bones making up this region of the animal skeleton. It also serves to enhance better understanding of its features when comparing with other ruminant domestic animals.

\section{Materials and Methods:}

The procurement of specimen carcass and experiments conformed to the
European Convention for the protection of Vertebrate animals used for scientific purposes (Council of Europe No. 123, Strasbourg 1985). Two adult (Male and female) West African giraffe (Giraffa camelopardalis peralta) carcass weighing $1,070 \mathrm{~kg}$ and $812 \mathrm{~kg}$ respectively were obtained after post-mortem from the Department of Veterinary Pathology, University of llorin at different periods of time. They were transported to the Veterinary Anatomy gross laboratory, University of llorin, Nigeria for bone preparation as museum specimens. They were carefully de-fleshed using sharp knife and scalpel blades. The skin was removed, and muscles teased out, leaving the bones with minimal soft tissue attachment before being transferred to a large container containing cold water enough to submerge the bones at room temperature. The container was covered airtight and placed under shade throughout the period of maceration with regular change of water. After completion, the water was drained, the bones recovered, and sun dried. Photographs of recovered bones were taken individually. They were also articulated using glue, noting the bones that constituted each segment of the vertebral column.

\section{Ethics:}

The procurement of specimen carcass and experiments conformed to the European Convention for the protection of Vertebrate animals used for scientific purposes (Council of Europe No. 123, Strasbourg 1985). The experimental protocols described were approved by the Ethics review committee for Animal experimentation of University of Ilorin, llorin, Nigeria. 


\section{Results:}

The axial skeleton comprised the skull (made up of large flat paired and unpaired bones) and the vertebral column (Cervical vertebrae, Thoracic vertebrae, lumbar vertebrae, sacral vertebrae and caudal vertebrae) which gave a formula of C7 T14 L5 S4 C15-18. They exhibited general and peculiar features similar to and different from other domestic animals studied. The average number of bones of the axial skeleton was found to be an average of 82 as shown in table 1.

The SKULL presented an elongated structure made up of caudal cranial bones and rostral facial bones all of which were flat and joined together by sutures (Figure 1.0). The cranial cavity was bounded caudo-dorsally and caudoventrally by unpaired parietal and occipital bones respectively, laterally by the paired temporal, dorsally by the paired frontal bones and rostrally by the ethmoid bone.

The Parietal bone presented a semiconcave external surface and four borders. The dorsal border articulated with the frontal bone medially and the erect processus cornus laterally. The two concave lateral borders joined the squamous part of the temporal bone to form the temporal fossa while the its ventral border joined the dorsal border of the occipital bone to form a crest like protuberance (Figure 1.3). The interparietal bone was clearly absent. The Occipital bone presented dorsal squamous, lateral and ventral basilar parts. All of which formed the boundaries of the foramen magnum. The squamous part articulated to the parietal dorsally and petrous part of temporal laterally
(Figure 1.3). The lateral parts, formed by the lateral paramastoid process and medial condyle were separated by a deep condyloid fossa that lodged the hypoglossal foramen (Figure 1.2). The ventral basilar part with a large tubercle articulated cranially with the sphenoid from which the vomer continued cranially to the ventral aspect of the nasal cavity. The sphenoid also presented medial vertical wings and lateral horizontal wings (which bore the large orbitorotundum, oval and optic foramina. Medial to this vertical wing was the pterygoid bone, a small flat thin quadrilateral bone ending ventrally in a Hamulus (Figure 1.2).

The squamous part of the temporal bone formed a lateral temporal fossa and concave articular surface for mandibular condyle articulation before extending its zygomatic process rostrally to articulate with that of the malar (Figure 1.1). It also presents a caudo-lateral temporal canal caudal to the articular surface for mandibular condyle articulation. This canal began from the foramen dorsal to the external acoustic meatus and opened caudally at the temporooccipital junction (Figure 1.1). The ventrally located petrous part was composed of a small irregular tympanic bulla (continued caudo-laterally to open as the external acoustic meatus while also ending rostrally with a short, sharp muscular process), styloid process (lodged between the bulla and the meatus) and mastoid process (placed caudally between the paramastoid process and temporal bone). The tympanic bulla adhered to the basilar part of the occipital creating a caudal jugular foramen (Figure 1.3). 
The paired frontal bone presented an extensive dorsal surface that was highly convexed at the middle (points of interfrontal suture). The lateral aspects of this surface bore the supraorbital foramen and groove from which spiral superficial vascular grooves radiated (Figure 1.0). Each frontal bone also extended a zygomatic process laterally that formed the external orbital margin. Its caudal border articulated with the parietal while its cranial border articulated with the nasal, formed the caudal border of the large frontal sinus and also articulated with the lacrimal bones. The Ethmoid bone formed the boundary between the cranial and nasal cavity. It presented the medial crista galli (facing the cranial cavity), medial perpendicular plate (facing the nasal cavity) and lateral sieve like cribiform plate.

The facial bones were made up of the nasal bone dorsally, the palatine and maxilla ventrally, the lacrimal, malar, turbinate, maxilla, premaxilla and mandible laterally. The paired nasal bone formed the roof of the nasal cavity. Its caudal border with straight and oblique ends articulated to the cranial border of frontal bone. Its ventrolateral border joined with the dorsal border of the maxilla only while its rostral border was valley-shaped giving rise to a double pronged projection (Figure 1.3). The Palatine bone presented a vertical and horizontal part. The vertical part continued cranial to the vertical wing of sphenoid forming the lateral borders of the posterior nares. The horizontal part formed the caudal part of the hard palate (Figure 1.3). The paired lacrimal bone which consisted of a facial part and an orbital part (lacrimal bulla) was placed laterally between the frontal bone caudally, maxillary bone cranially and large frontal sinus medially. It presented an irregular shape and formed the medio-rostral border of the orbit (Figure 1.2). The paired malar bone was placed between the orbit dorsally and the maxilla ventrally forming the ventral margin of the orbit, before extending an orbital process dorsally and a zygomatic process caudally that articulated with the orbital process of the frontal and zygomatic process of the temporal respectively (Figure 1.2).

The paired Maxilla formed majority of the lateral wall of the nasal cavity, anchoring the upper premolars and molars ventrally via its alveolus. Its dorsal and rostral border articulated with the nasal and premaxilla bones while its caudal border formed the cranial margin of the frontal sinus as well as articulating with the lacrimal and malar bones. It also extended ventrally to form its palatine process that bore the palatine foramen caudally. Ventrally, just rostral to the first premolar, the maxilla presented a large infraorbital foramen (Figures 1.2 and 1.3). The paired premaxilla was placed rostral to the maxilla forming the rostro-lateral part of the nasal cavity. It presented a lateral body, dorsal nasal process and a ventral flat palatine process while forming a small ventral palatine fissure between the processes. The inverted U-shaped inter-incissive fissure was seen rostral to the inter-incissive suture (Figures 1.1, 1.2 and 1.3). The paired Turbinate bones on the internal wall of the nasal cavity, were three in number (dorsal, middle and ventral) having a scroll-like fenestrated appearance. 
The Mandible comprised two halves joined rostro-medially by the symphysis. Each half presented a rostral body, horizontal and vertical rami. The body anchored the incissors rostro-dorsally via its alveolus and bore the mental foramen laterally. The horizontal ramus continued caudally after the body, anchoring the premolars and molars on its concave dorsal border via the alveoli. A dorsal mandibular crest was formed between the incissors and first premolar. This formed the ventral border of the diastema. The vertical ramus presented on its dorsal border, a rostral caudally directed coronoid process and a caudal mandibular condyle separated by the sigmoid notch. On its medial surface, it bore the mandibular foramen (Figure 1.4). The VERTEBRAL COLUMN comprised different segments made up of individual vertebral bones each consisting of a body and an arch constructed dorsally to enclose the large median vertebral foramen with processes and foramina present.

Despite the neck length, the cervical vertebrae were seven in number. However, each were elongated. The Atlas (Figure 2.0) presented a body with a concave cranial articular facet, flat caudal articular facet and ventral tubercle. The arch with a dorsal tubercle formed dorsal to the body thereby enclosing the large vertebral foramen. Its short wings (bearing the inner lateral vertebral and outer alar foramina) end as a concave crest laterally and continues as a process caudoventrally beyond the body. The atlanta fossa on the ventrum of the wings was shallow while the transverse foramen was absent.
The Axis (Figure 2.1) presented an odontoid process having a dorsal concave and ventral convex surface that projected craniomedially from the body. It was flanked by the cranial articular facet. The lateral vertebral foramen opened craniolaterally into the large vertebral foramen while the transverse foramen was evident as a canal through the rudimentary transverse process. The caudal articular process projected dorsolaterally over the body while the spinous process extended the entire length of the arch forming a crest as it hangs over the odontoid process.

The 3rd - 7th cervical vertebrae (Figure 2.2) presented the typical configuration of a vertebra in that they possessed centrum with convex cranial and concave caudal facets; spinous process dorsomedially; cranial and caudal articular processes with facets facing dorsal and ventral respectively; cranial transverse processes directed obliquely and transverse foramen parallel to the centrum. The $7^{\text {th }}$ cervical appeared shorter while the ventral process was absent.

The Thoracic vertebrae (Figure 2.3) were 14 in number and presented bodies bearing coastal facets on their surfaces; short transverse processes bearing coastal facets and long spinous processes. Caudal coastal facet was absent on the body of the $14^{\text {th }}$. The transverse process decreased in size throughout the series while mammillary processes were evident from the 3 rd to the $14^{\text {th }}$. The spinous processes increased in length caudally, peaking at the $4^{\text {th }}$ before diminishing towards the $14^{\text {th }}$. The features of the $1^{\text {st }}$ were larger than any other in the series and also possessed a 
ventral process from the centrum (Figure 2.4).

Long transverse processes with increasing concavity of the cranial borders through the series were prominent features of the Lumbar vertebrae (Figure 2.5). Their short and wide spinous process ended sharply as a convex crest.

The Sacrum (Figure 2.6) was a fusion of 4 bones. It presented a triangular shape, the first being the largest and featured cranial articular processes, lateral wings with auricular surface at its border for ilium articulation. The spinous process of the first appeared to stand alone while the rest fused forming a medial sacral crest. Their cranial articular processes also formed a somewhat rudimentary lateral sacral crest. 3 dorsal and ventral sacral foramina were identified laterally on each side of the vertebrae.

The Caudal vertebrae (Figure 2.7) presented two different portions of varying shapes and sizes craniocaudally. The cranial portions presented the typical vertebral features which diminished gradually through the series. The caudal portions presented only the bodies.

The ribs presented a dorsal bony and ventral cartilaginous part; the costal cartilage. The proximal extremity of each rib presented a head, neck, and a tubercle which articulated with the corresponding facets of the thoracic vertebrae. The body presented concave inner and convex outer borders; lateral and medial surfaces lined by coastal groove. The sternum (Figure 2.8) was composed of 5 Sternebrae fused together via cartilage which was lost during maceration.

\section{Discussion:}

The West African Giraffe (Giraffa Camelopardalis peralta) presented an elongated skull with erect cornual process (Ossicone). This presentation was similar to what was obtained in most domestic animals except the cornual process which was present in males of ovine species, large ruminants but absent in the horse, pig and dog (Pasquini et al., 1997, Budras et al., 2007).

The Parietal bone was unpaired, extensive and located entirely on the caudal aspect joining the dorsal border of the occipital to form a crest-like occipito-parietal protuberance. This was only similar to that seen in the sheep (Adams and Crabtree, 2012). It was reported to be paired, extensive and dorsally located in the horse, pig and dog (Konig and Liebich, 2004) while in the cattle and goat, it was paired, small and caudally located (Hussain, 2010). As seen in the dog (Evans and Delahunta, 2013), the foramen magnum was formed by the three parts (Squamous, lateral and basilar) of the occipital bone. The absence of the lacerated foramen was similar to other domestic animals except the horse (Budras, et al., 2009). Also, its prominent basilar tubercle was only seen in the cattle (Ashdown and Done, 2010). The highly convexed middle part of the frontal bone was specific to this species as this feature has not been reported in any known animal species studied. This feature highly suggested that the Giraffe may have a large brain with a possibly raised frontal lobe of cerebrum or enlarged olfactory bulb as this convex portion articulated with the equally convex caudal border of the nasal bone. This suggestion was further complimented by two additional features; the short nasal 
bone with its valley shaped double pronged rostral projection and the large irregular shaped frontal sinus. These features create more space for accommodation of muscular nostrils that normally closes to protect against sandstorms (Swaby, 2010) and help to accommodate more air when breathing from such high altitude due to its height (Prothero and Schoch, 2003). The spiral shallow grooves radiating from the supraorbital foramen was also a unique feature of this species, these grooves house tiny blood vessels that either branch out or drain into the supraorbital artery or vein respectively. As reported in most ruminants (Budras and Habel, 2003), the diastema was evident and the premaxilla had no alveoli for upper incissor anchorage. The presentation of the mandible was similar only to that seen in the ruminants and horse (Konig and Lebich, 2004).

The most outstanding feature of the Vertebral column in this species was the very long cervical vertebrae which gave the animal a correspondent long neck compared to other mammalian species although the common number of seven (7) cervical segment was recorded. The vertebral formula of C7 T14 L5 S4 C15-18 was unique, most notably based on the number of thoracic and lumbar vertebrae which has been reported to be 13 and 6 respectively in most ruminant species (Dyce, 2010).

The Atlas presented short narrow wings which ended as a concave crest laterally and continued as a process caudoventrally beyond the body. This finding was unique and specific to this species. Its lack of transverse foramen was similar to ruminants and pig (Konig and Liebich, 2004). The disproportionate lengthening of the cervical vertebrae (Swaby, 2010) resulted in the oblique orientation, ventral positioning of the transverse processes and disappearance of the ventral process of the $3^{\text {rd }}$ to $7^{\text {th }}$ vertebrae. The presence of the ventral process on the $1^{\text {st }}$ thoracic vertebrae was also a specific feature for this species as no other reported species possessed this. The sacrum presented features that can be said to be similar to the ruminants however, the $1^{\text {st }}$ sacral vertebra was not involved in the fusion of the spinous process. The features of the caudal vertebrae conformed with that reported in most other species.

\section{Conclusion:}

This study on the Gross anatomy of the Axial skeleton of the West African Giraffe (Giraffa Camelopardalis peralta) presented the numerical and morphological information on bones of this animal skeleton highlighting specific features, similarities and differences from other ruminant and domesticated animals.

\section{Acknowledgement:}

The Academic and Technical staff of Department of Veterinary Pathology, Faculty of Veterinary Medicine, University of llorin, Nigeria are appreciated and acknowledge for their assistance in acquiring the carcasses for this work.

\section{Funding}

This research did not receive any specific grant from funding agencies in the public, commercial, or not-for-profit sectors.

\section{Conflict of Interest:}

Authors declare that no conflict of interest is associated with this work.

\section{Data availability statement:}


Data sharing not applicable to this article as no datasets were generated or analysed during the current study.

\section{References:}

Adams, B and Crabtree, P. (2012). Comparative Osteology: A laboratory and Field Guide of common North American Animals. Academic press. Oxford, U.K. pp. 156-214

Ashdown, R. R and Done, S.H. (2010). Color Atlas of Veterinary Anatomy Vol. 1: The Ruminants. $2^{\text {nd }}$ edition. Mosby Elsevier. Pp. 3, 28.

Bercovitch, F.B., Berry, P.S.M; Dagg, A., Deacon, F., Doherty, J.B, Lee, D.E., Mineur, F., Muller, Z., Ogben, R., Seymour, R., Shorrocks, B and Tutchings, A. (2017). "How many species of giraffe are there?". Current Biology. 27 (4): R136-137. Bolger, D., Ogutu, J., Strauss, M., Lee, D. Muneza, A., Fennessy, J., Brown, D. (2019). "Masai Giraffe" IUCN Red list of Threatened Species.

Budras, K. and Habel, R.E. (2003). Bovine Anatomy: An Illustrated text. First edition. Schlutersche $\mathrm{GmbH}$ and Co. Hannover, Germany. Pp. 35.

Budras, K., Mc-Carthy, P. H., Horowitz, A. and Berg, R. (2007). Anatomy of the Dog. Schlutersche Hannover, Germany. Pp. 40. Budras, K., Sack, W. O and Rock, S. (2009). Anatomy of the Horse. $5^{\text {th }}$ edition. Schlutersche Hannover, Germany. Pp. 3335.

Dyce, K.M., Sack, W.O and Wensing, C.J.G. (2010). Text book of Veterinary Anatomy. Saunders Elseviers, St. Lois Missouri. U.S.A. $4^{\text {th }}$ edition. Pp 407-414.

Evans, H.E and De-lahunta, A. (2013). Miller's Anatomy of the Dog. Elsevier Saunders. U.S.A. pp. 85-126.
Fennesey, J., Marais, A., Tutchings, A. (2018). "Giraffa camelopardalis peralta" IUCN Red list of Threatened Species.

Fennessy, J., Bidon, T., Reuss, F., Kumar, V., Elkan, P., Nilsson, M.A., Vamberger, M., Fritz, $U$ and Janke, A. (2016). "Multi-locus analysis reveal four giraffe species instead of one". Current Biology. 26 (18): 25432549.

Foley, C., Foley, L., Lobora, A., De Luca, D., Msuha, M., Davenport, T. R. M and Durant, S.M. (2014). A field Guide to the Larger Mammals of Tanzania. Princeton University Press. Pp. 179.

Hassanin, A., Ropiquet, A., Gourmand, B.L., Chardonnet, B., Rigoulet, J. (2007). "Mitochondrial DNA variability in Giraffa camelopardalis: consequences for taxonomy, Phylogeography and conservation of giraffes in West and central Africa". Comptes Rendus Biologies 330 (3): 173-183.

Hussain, M.S (2010). Essentials of Caprine Anatomy. 1st edition. Faculty of Veterinary Science, University of Agriculture, Faisalabad. Pp.10-22.

Kingdon, J. (1997). The kingdon field guide to African Mammals. Academic Press. Pp. 339-344.

Konig, H.E and Liebich, $H$ (2004). Veterinary Anatomy of Domestic mammals: Textbook and colour Atlas. Schattaver, Stuttgart, Germany. Pp. 27-90 Muller, Z., Bercovitch, F., Brand, R., Brown, D., Brown, M., Bolger, D., Carter, K., Deacon, F., Doherty, J.B., Fennessy, J., Fennessy, S., Hussein, A.A., Lee, D., Marais, A., Strauss, M., Tutchings, A and Wube, T. (2016). "Giraffa camelopardalis" IUCN Red list of Threatened Species.

Pasquini, C., Spurgeon, T. and Pasquini, S. (1997). Anatomy of Domestic Animals: 
Systemic and Regional approach. SUDZ Publishing, U.S.A. pp. 35-56.

Pellow, R.A. (2001). "Giraffe and Okapi", In MacDonald, D. (ed.). The Encyclopedia of Mammals of the World. Vol.1. The Sternum Johns Hopkins Ribs University Press.

\begin{tabular}{l|l} 
Bones & Number \\
\hline Skull & 1 \\
Mandible & 1 \\
Sternum & 5 \\
Ribs & 28 (14 pairs) \\
Cervical vertebra & 7 \\
Thoracic vertebra & 14 \\
Lumbar vertebra & 5 \\
Sacral vertebra & 4 \\
Caudal vertebra & $15-18$ \\
\hline Total average: & $\mathbf{8 0 - 8 3 ( A v . ~ 8 2 )}$
\end{tabular}

Baltimore, U.S.A and Lnondon, U.K.

Prothero, D.R and Schoch, R.M. (2003). Horns, Tusks and Flippers: The Evolution of Hoofed Mammals. John Hopkins University Press. Pp. 67-72.

Swaby, S. (2010). "Giraffe". In Harris, T. (ed.). Mammal Anatomy: An Illustrated Guide. Marshall Cavendish. Pp. 64-84.

TABLES:

Table 1: Number of bones of the Axial Skeleton of the Giraffe (Giraffa Camelopardalis peralta)

FIGURES:



Figure 1.1 


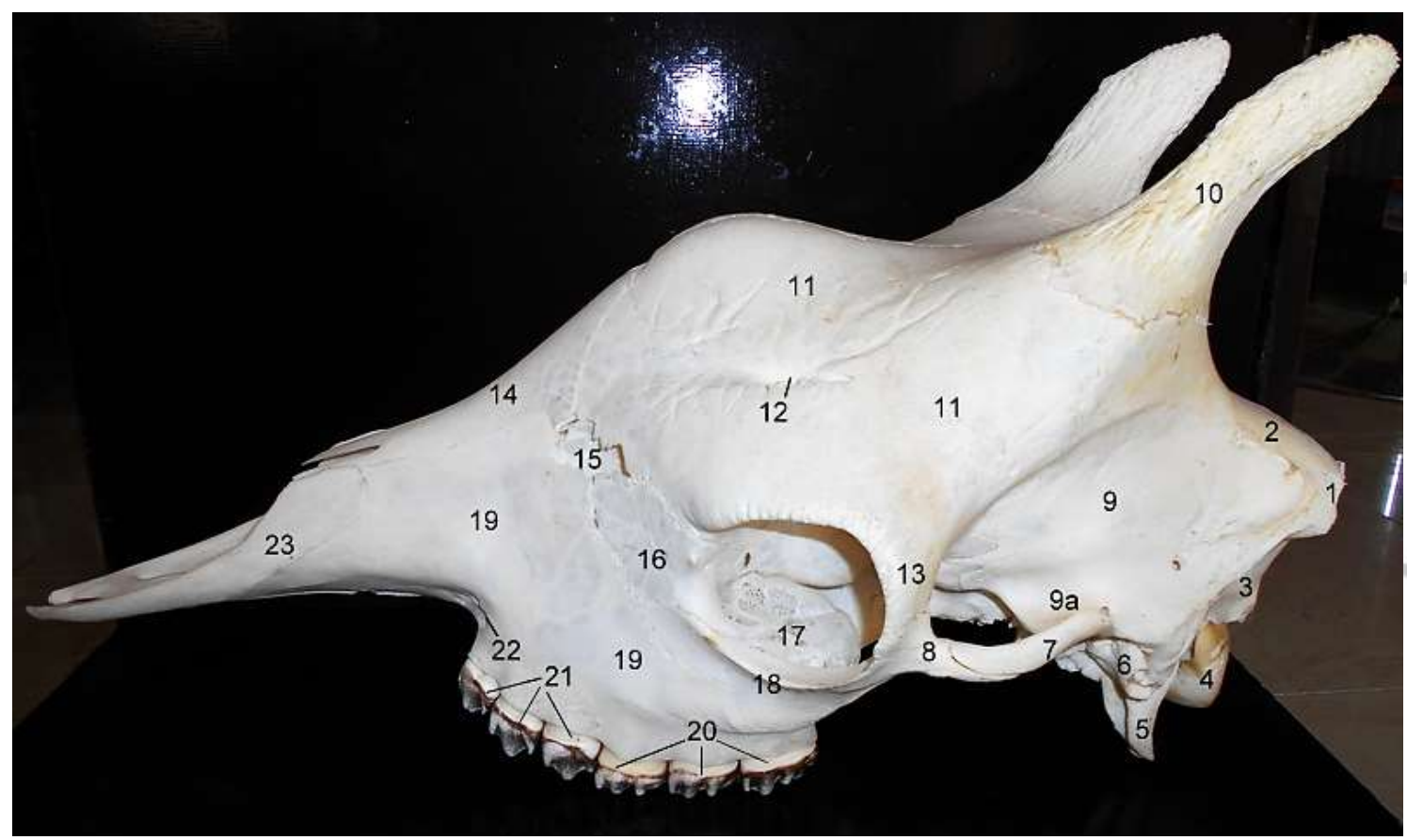

Figure 1.2

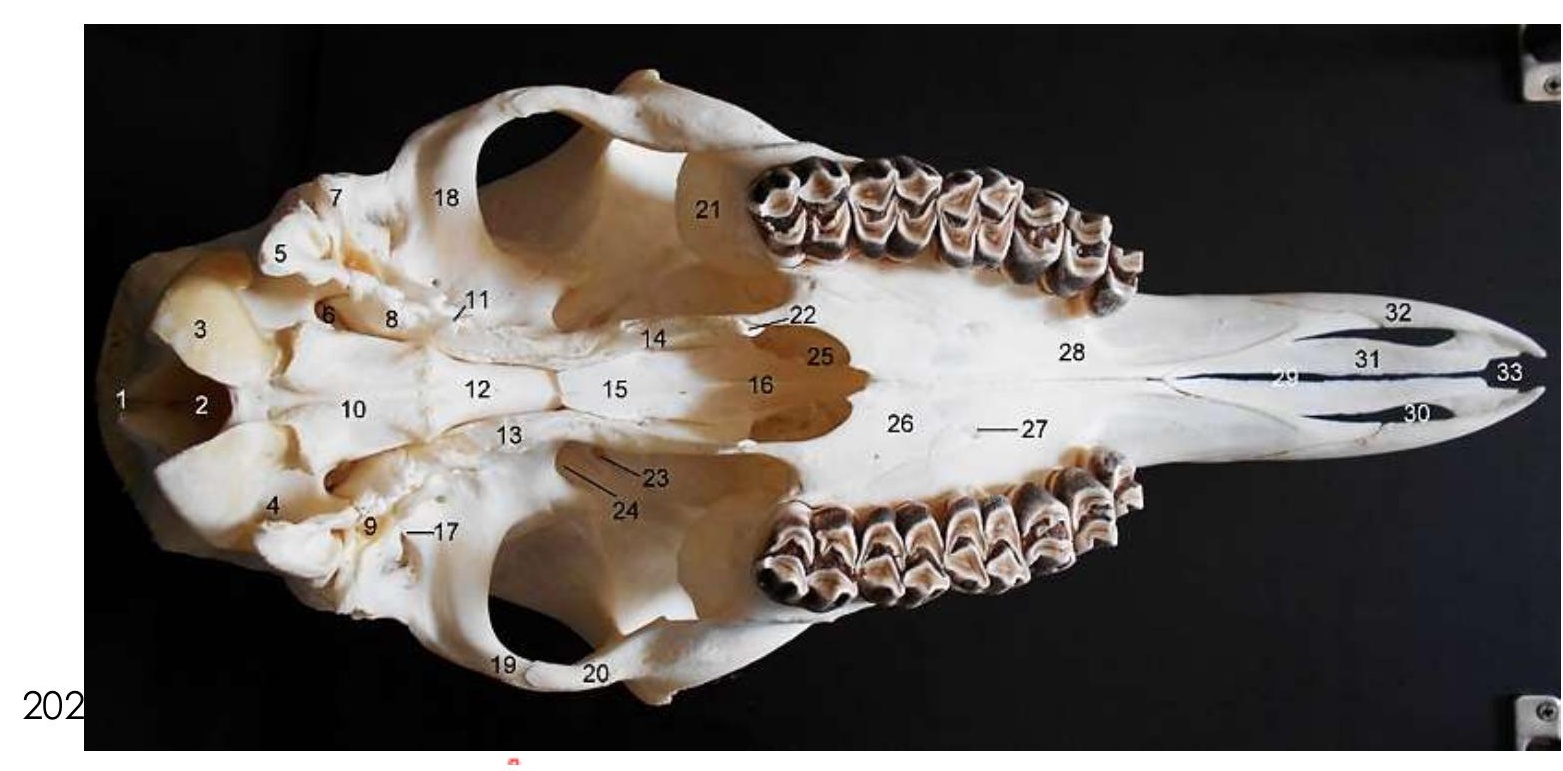

Figure 1.3 


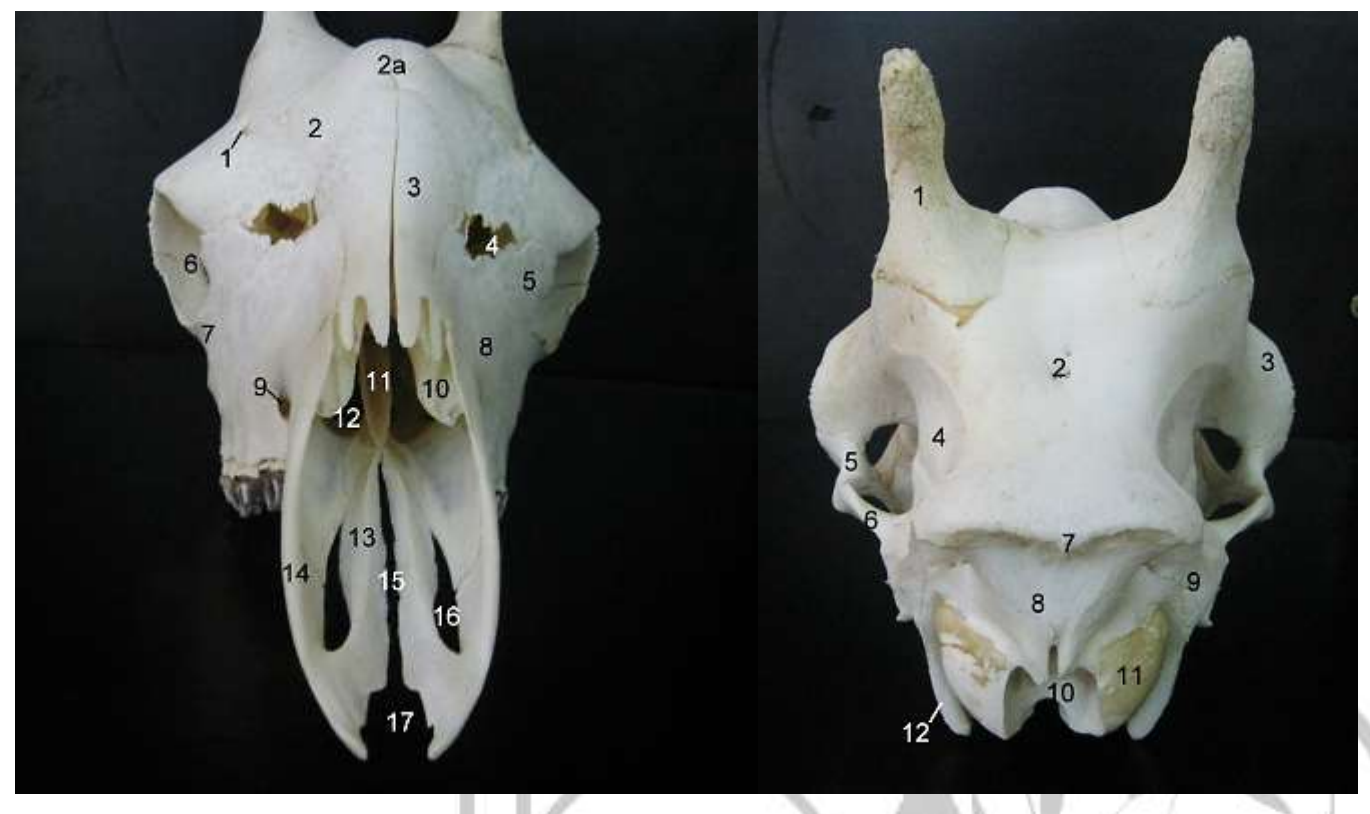

Figure 1.4
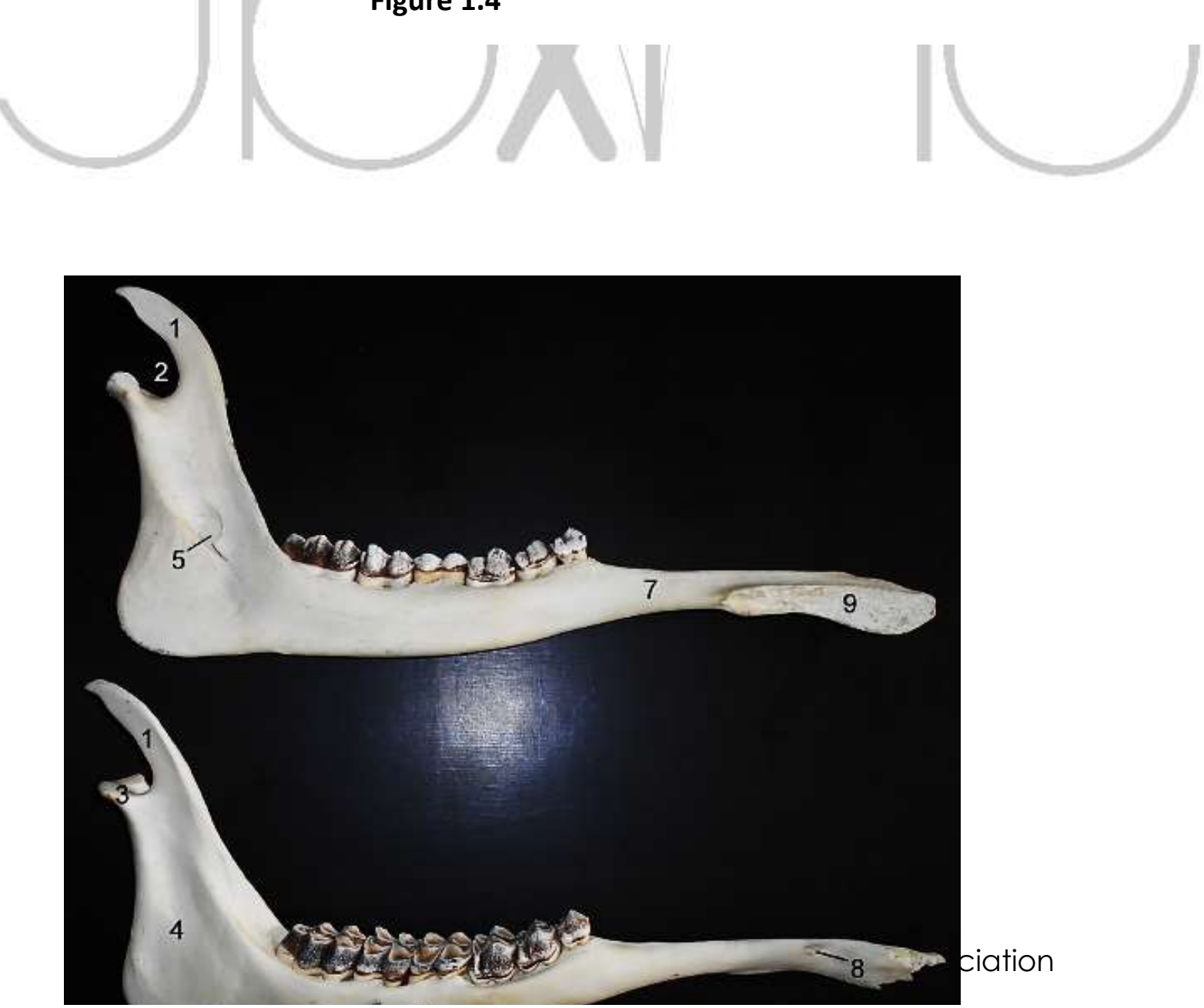

Figure 1.5 


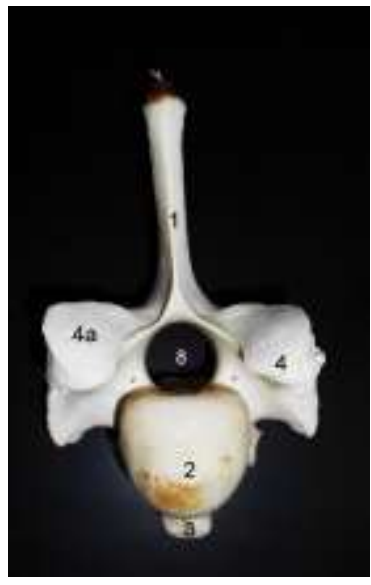

Figure 2.4

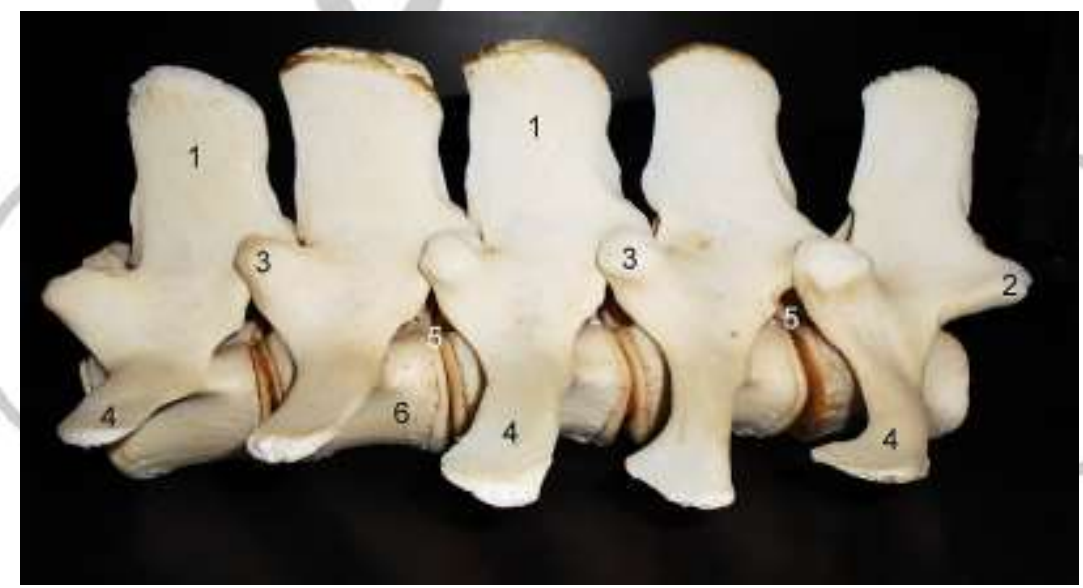

Figure 2.5

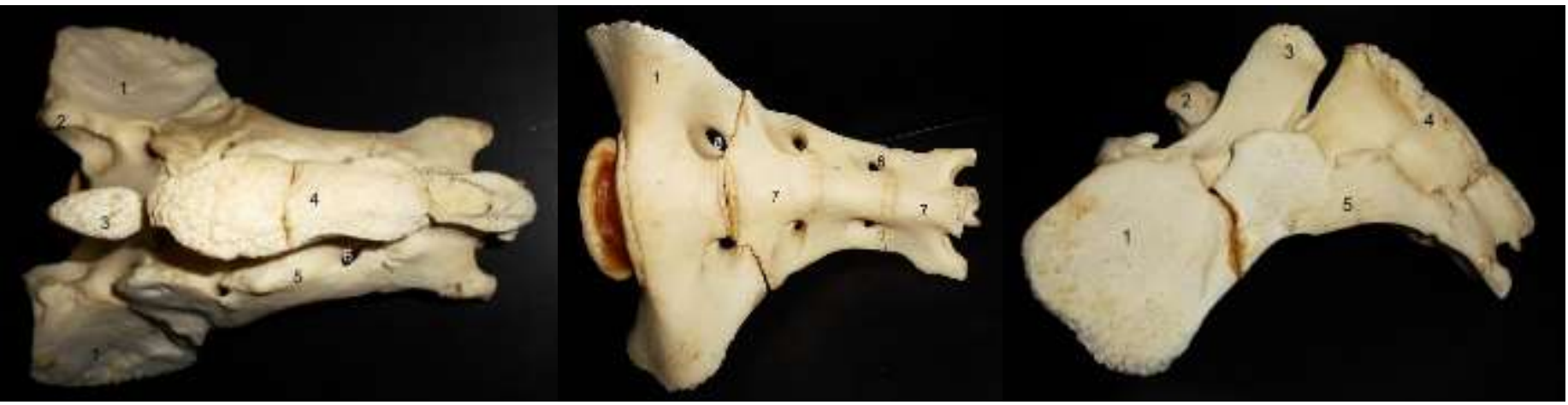

Figure 2.6

2021 July Edition | www.jbino.com | Innovative Association 


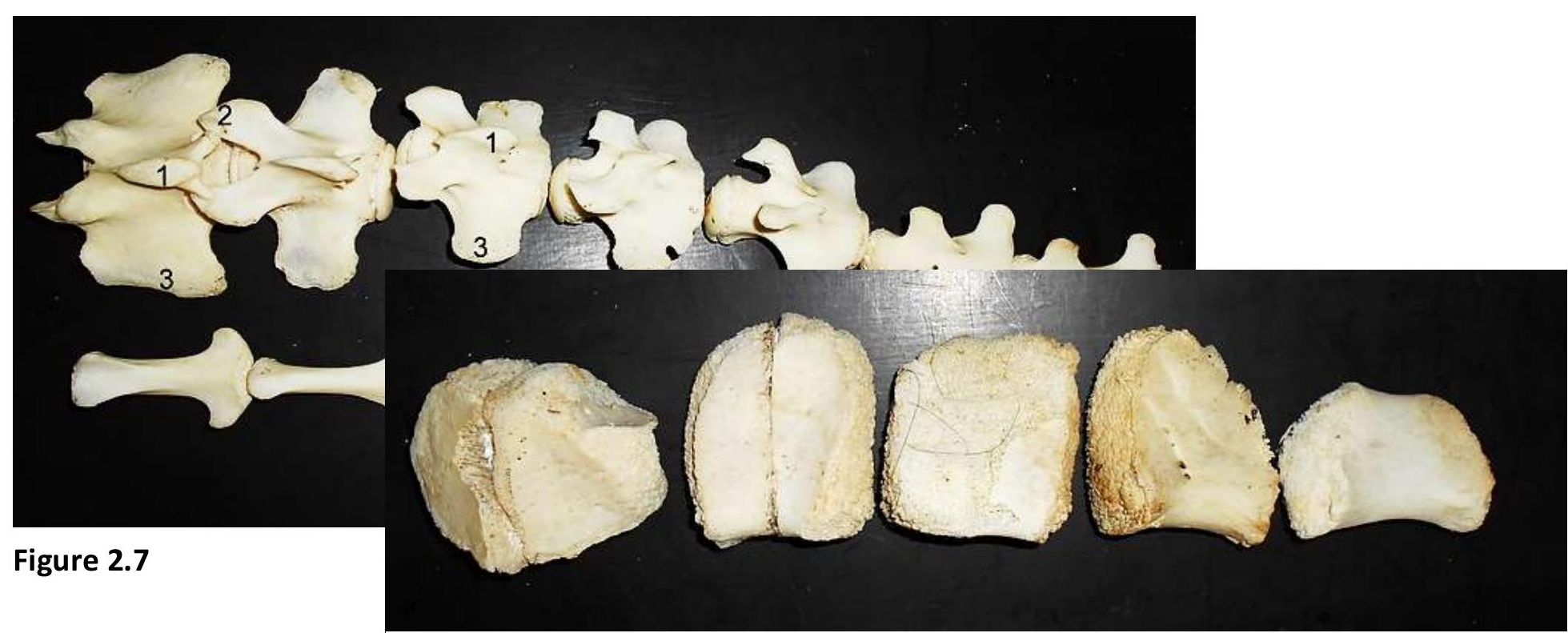

Figure 2.8

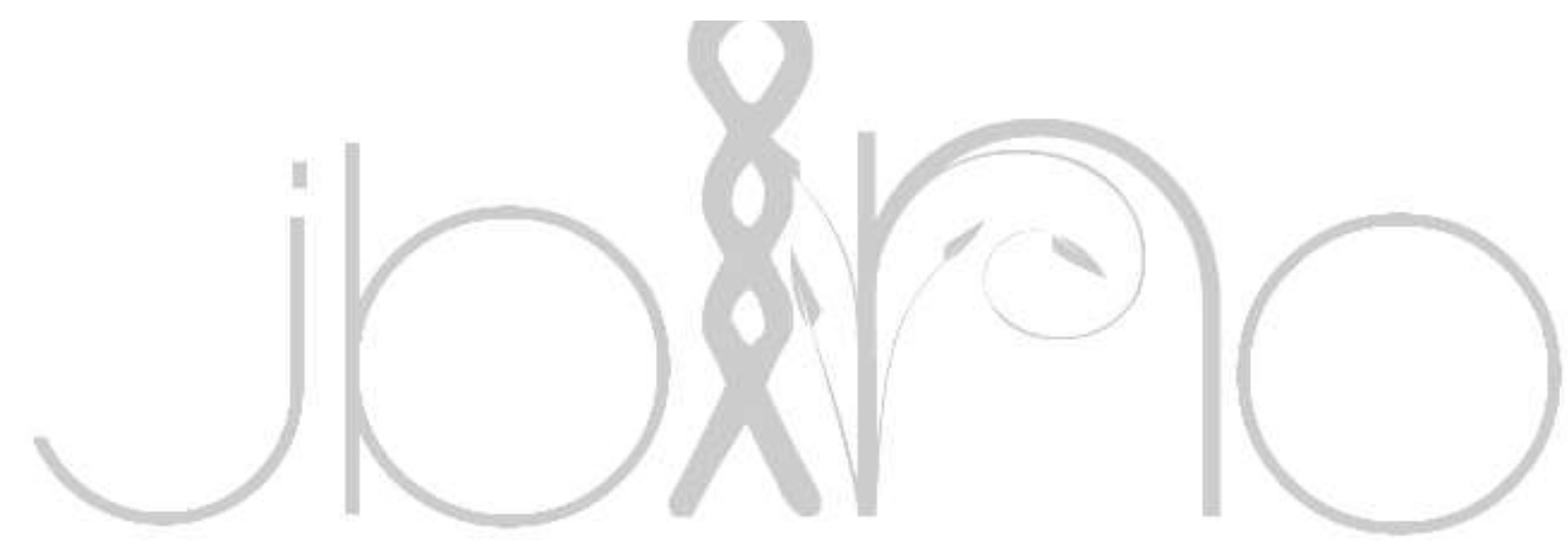

